\title{
CONTRIBUTIONS TO THE MORPHOLOGY OF CERCARIAE OBTAINED FROM A SNAIL HOST, SEMISULCOSPIRA LIBERTINA IN JAPAN
}

\author{
JIRO ITO \\ Hygiene Laboratory, Faculty of Education, Shizuoka University, Shizuoka, Japan
}

(Received: December 26th, 1959)

Fresh water snails, Semisulcospira libertina, including $S$. reiniana and S. japonica, are known as the first intermediate hosts of pathogenic trematodes, e.g. Paragonimus, Metagonimus, etc. These snails are also infected with many other non-pathogenic cercariae, the majority of which have been described up to now incompletely. Therefore, in the case of epidemiological studies, research workers used to be confused on the differentiation of cercariae.

In order to correct such meagre descriptions, the author have already carried out many investigations regarding the morphology of carcariae. More than 18 species of cercariae were detected from Semisulcospira libertina by the author in the past ten years, 1949 to 1959 . Ten species of them were already described in details (Ito, 1950, $1952 \mathrm{a}, 1952 \mathrm{~b}$, $1953 \mathrm{a}, 1953 \mathrm{~b}, 1956,1958,1959,1960)$.

In this paper, another seven species of cercariae are presented and described on their morphological differences; i.e. two furcocercous-, one echinostome-, one xiphidio-, two tailless-, and one cysticercous-cercaria. Among them, four are the redescriptions, while the other three are given a new name respectively.

\section{MATERIALS AND METHODS}

Cercariae and rediae were obtained from the snail hosts by crush procedure or by making them emerge from the host in a natural way. Materials were taken in $0.4 \% \mathrm{NaCl}$-solution and pressed by a coverglass till they became very thin, flat and transparent, so as to be most convenient for morphological observations especially of the excretory system. These materials could be preserved for the observation of a few hours when the margin of the coverglass was sealed with vaseline. The vital staining with neutral red or nile blue sulphate was useful for discrimination of detailed structures. Measurements were taken on materials fixed in 10\% hot formalin, because the results obtained in this way were relatively consistent. All drawings were made to scale from such materials.

\section{Cercaria pseudodivaricata Faust, 1924 (Figs. 1 \& 2)}

A brief description of one species of furcocercous cercaria has been reported by Ando (1918), who obtained it from Semisulcospira libertina in Gifu Prefecture as "Cercaria No. 9". Later on, a proper name, Cercaria pseudodivaricata was given to it by Faust (1924) without any redescription.

The present author had two chances of getting specimens of one species of pharyngeal longifurcate distome cercariae from $S$. libertina in Shizuoka Prefecture. As far as Ando's

伊藤二郎（静岡大学教育学部保健研究室） 
original description shows, the present fork-tailed cercaria is identifiable with Cercaria pseudodivaricata. The following is a detailed description of the species.

Parthenita (Fig. 1)...... The parthenitae are irregular cylindrical sporocysts, measuring $0.62-3.06 \times 0.043-0.35 \mathrm{~mm}$. It has a thin, transparent body wall without neither spines, nor hairs, nor birth pore. Many equally developed cercariae are contained in the sporocyst.

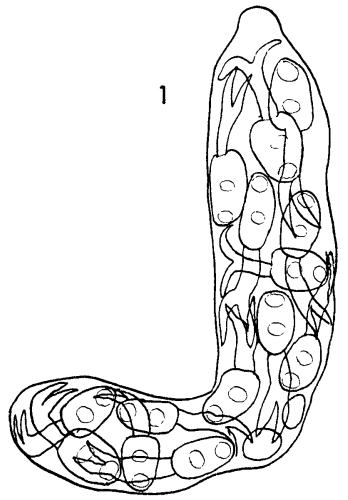

Fig. 1. Mature sporocyst Cercaria pseudodivaricata.

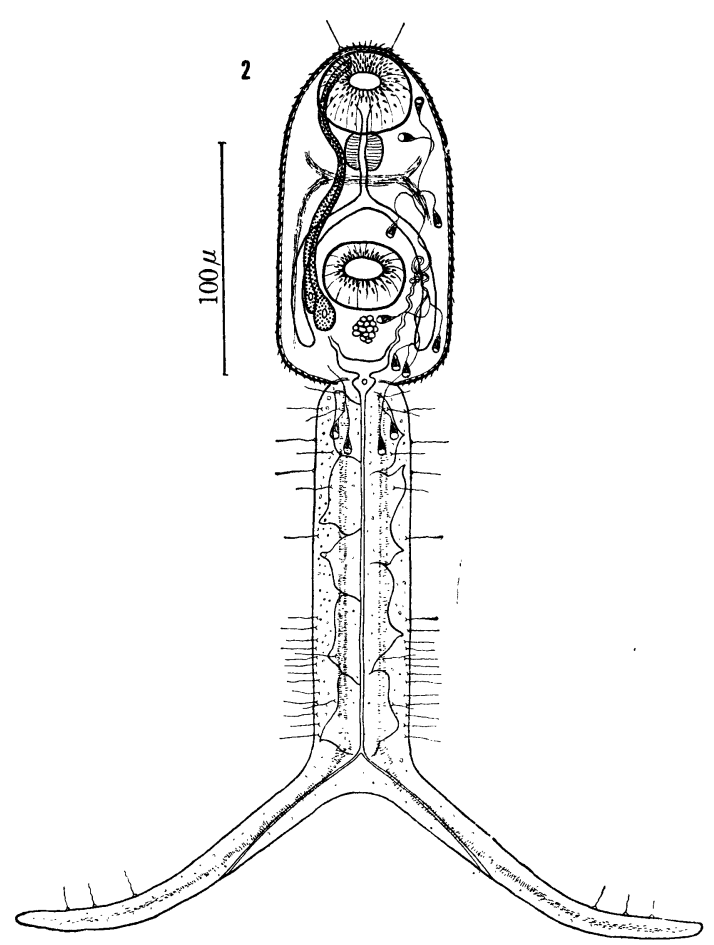

Fig. 2. Cercaria of C. pseudodivaricata.

Cercaria (Fig. 2)......The cercaria is one of the transparent, moderately sized pharyngeal longifurcate distome types with a character of Strigeata or Diplostomatidae. The body is capable of extension and contraction to a considerable degree. In a semi-contracted condition, the body has a pyriformed outline, the anterior part being tapered, and the posterior part being more blunt. The measurements are as follows.

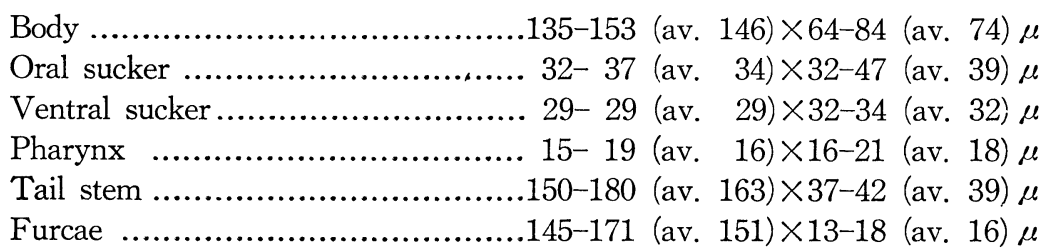

The body surface is covered with many minute spines directing their tips backwards, while particularly larger spines are found on the ventral part of the anterior extremity 
around the mouth opening. One pair of sensory hairs is observed at the anterior part of the body.

A well developed oral sucker occupies the anterior part of body. A ventral sucker, being situated at the posterior two thirds of the body, is slightly smaller than the oral sucker, and is provided with circularly arranged small spines around the opening. The mouth is subterminal and leads back into a muscular pharynx which is followed by a moderately long esophagus. Two long ceca extend to the level of the excretory bladder. Two pairs of penetration gland cells lie at each side of, or behind, the acetabulum. Their ducts pass forwards to open on the tip of the snout. A nervous commissure is recognized across the esophagus. It divides into an anterior and a posterior nerve cords at the both lateral extremities. The genital primordium is present behind the ventral sucker as an oval shaped mass of cells.

A thin walled, and cup-shaped excretory bladder is located at the posterior part of the body. One pair of main collecting tubes arise from the antero-lateral corner of the excretory bladder. These collecting tubes run forwards in zigzag course, then divide into an anterior and a posterior collecting tube respectively at the level of acetabulum. The anterior tube runs forwards receiving four flame cells in two groups, and the posterior one runs backwards getting four flame cells in this way within the body, then enters into the tail, where it terminates in two flame cells. Thus the flame cell formula of this cercaria is demonstrated as $2[(2+2)+(2+2+[2])]=20$. A caudal excretory tube arises from the posterior end of bladder, and after passing backwards to the distal end of tail stem, it divides into two branches, each of which passes along the corresponding furcal ramus and opens at the mesial inner side of the ramus respectively. An excretory pore and a typical Island of Cort are recognized at the point where the caudal excretory tube joins the bladder.

A comparatively large tail is attached to the end of body. The surface of tail stem is provided with more than twenty pairs of sensory hairs standing on a papilliform base respectively. They are arranged at irregular intervals, being more dense on the posterior half part of tail stem. Three pairs of such hairs are also located on the posterior part of tail furcae. In addition, many extremely minute spines are observed along the tail surface in two longitudinal strands as figured in Fig. 2. Several irregular vacuolated masses are found surrounding the caudal excretory canal.

Discussion...... The incidence of this cercaria in the snail was very rare. In spite of the comprehensive surveys in Japan, especially in Shizuoka Prefecture, this cercaria was found on only two occasions. One occasion arose at Fujioka Village in 1944, where only one was found out of 93 snails, and the other was at Oohama-Cho in 1957 where 5 was found out of 116 snails. In total, 6 out of 34060 , or $0.02 \%$, of all the snails tested were infected with this cercaria in Shizuoka Prefecture. Ando (1918) also reported such low infection rate of this cercaria as 8 out of 21118 , or $0.04 \%$, in Gifu Prefecture. Ueno et al. (1930) reported one species of furcocercous cercaria, Cercaria E, from the same species of snails in Kyushu Province. According to their description and figures, it is identifiable with the present species, though their description is very fragmental.

The present species of cercaria has a strong resemblance to the cercaria of Diplostomum baeri eucaliae (Hoffman and Hundley, 1957), but differs from it in some detailed structures. It is probable that the present cercaria will develop to a member of the family Diplostomatidae. It is revealed by the present author that a fresh water fish, Ophicephalus argus harbours one spcies of metacercaria belonging to the genus, Neodiplostomum, in 
Shizuoka Prefecture (unpublished). So it may be considered that this metacercaria and the present cercaria may be the same species of the genus, Neodiplostomum.

\section{Cercaria redicola Faust, 1924 (Fig. 3)}

One species of furcocercous cercaria from Semisulcospira libertina was briefly described by Kobayashi (1922) in Korea. Faust (1924) gave it a new name, Cercaria redicola.

The author have encountered a species of furcocercous cercaria from Semisulcospira libertina on two occasions. The one arose in snails from Kochi Prefecture in 1950, the other arose in snails from Niigata Prefecture in 1954, and the infection rate was very low on both occasions. This cercaria has a character of the Vivax group, the third one in Japan, and is identifiable with Cercaria redicola, as far as the original description shows. A redescription of this cercaria is presented here, though detailed observations as well as its measurements have not yet been done.

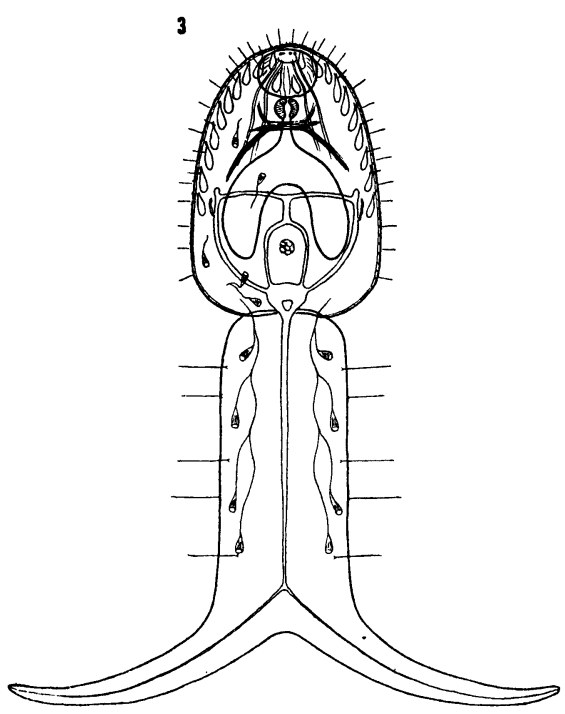

Fig. 3. Cercaria of C. redicola.

Cercaria (Fig. 3)......The body is oval in shape, tapering and somewhat rounding in its anterior part. The body surface is covered with minute spines directing their tips backwards, while larger spines are found particularly on the antero-ventral part around the mouth opening. The body surface is also provided with more than 20 pairs of sensory hairs standing on a minute papilliform base respectively.

The anterior part of body is occupied by a moderately sized oral sucker. The mouth is subterminal and leads back into a small but well-developed pharynx which is followed by a short esophagus. Thin walled ceca are remarkably broad, and extend to the level of a rudimentary acetabulum. This acetabulum is so faintly recognized with a great effort as a small mass of cells. Penetrating gland cells are not detected, but two pairs of their duct-like strings are observed. So-called head glands are situated in the oral sucker. There are another glandular cells located at the dorso-lateral side except the posterior part. 
These elongated small cells open respectively by a short duct to the body surface.

The excretory system is characteristic of the Vivax group. A thin walled small exceretory bladder receives four ascending trunks, one pair of which is median in position and the other is lateral. The pair of the median trunks run forwards separately, then join each other on the way to form a common median trunk. This median trunk extends anteriorly almost up to behind the esophagus where it divides into two laterally horizontal branches across the intestinal ceca, and joins the lateral ascending trunks respectively. One pair of collecting tubes arise from the lateral ascending trunk, slightly posterior to the above mentioned junctions. Several flame cells can be detected but the materials are too few and unsuitable to observe the exact flame cell pattern.

The nervous commissure is recognized across the esophagus. It divides into an anterior, a median and a posterior nerve cord at the lateral extremities.

A large forked tail is attached to the posterior dorsal end of the body. About five pairs of sensory hairs are located on the surface of tail stem in irregular intervals. A caudal excretory tube arises from the posterior end of the bladder and, after passing backwards to the distal end of tail stem, divides into two branches, each of which passes along the corresponding furcal ramus to its extreme tip. There are four pairs of caudal flame cells in the tail stem.

\section{Cercaria chromatocerca n. sp. (Figs. 4-8)}

Host : Semisulcospira libertina (Gould).

Locality : Hatta-Gun, Kochi Prefecture, Japan.

Specific diagnosis: Long-tailed echinostome cercaria. Body, 122-144 (av. 135) $\mu$ long by $76-90$ (av. 85) $\mu$ wide, is ellipsoidal in shape. Body surface has no spines but several pairs of sensory hairs on the anterior part. Oral sucker, $35-38$ (av. 37) $\mu$ long by 38-41 (av. 39) $\mu$ wide, is provided with about ten small hairs on its antero-ventral margin. Acetabulum is larger than the oral sucker, 38-46 (av. 41) $\mu$ long by 41-43 (av. 41) $\mu$ wide, and situates at the posterior part of body. Prepharynx, 4.1-10.8 (av. 6.2) $\mu$ long, is followed by pharynx which is 16-19 (av. 17) $\times 14-16$ (av. 15) $\mu$ in size. A long esophagus divides into two ceca just in front of acetabulum. Ceca reach to the posterior end of body. Cystogenous materials are compacted within the body cavity. Nervous commissure and genital primordium are faintly recognized.

Excretory system is characteristic of echinostome type. Bladder is composed of two rooms. No excretory concretions in ascending collecting tubes, but four or six groups of cilia in descending tubes. Flame cell formula is $2[(1+1+1+1)+(1+1+1+1)]=16$.

Tail has a vigorous power of extension and contraction. It measures 558-897 (av. 695) $\times 33-46$ (av. 39) $\mu$ in extended condition, and 198-290 (av. 246) $\times 49-68$ (av. 56) $\mu$ in contracted condition. The another character of tail is a brilliantly coloured design, namely, light yellow in the first quarter length, brilliant orange or redish brown in the middle half length, and entirely colourless in the last quarter length. Distal end of tail is modified as a bulbous holdfast organ.

Rediae, 0.5-1.5 (av. 0.8) $\mathrm{mm}$ long by 0.2-0.5 (av. 0.3) $\mathrm{mm}$, are echinostome type. About ten pairs of flame cells in the body wall of redia. Pharynx, 48-62 (av. 54) $\times 46-54$ (av. 50) $\mu$ in size, is followed by a long intestine reaching to the posterior half of redia. The intestine has brownish pigmented food granules. About twenty of matured cercariae and thirty of germ balls are contained in the body cavity of redia.

This cercaria is one of the rare species. The author have encountered with them once in snails from Kochi Prefecture in 1953. The most peculiar character of this cercaria is that it has a differentially coloured large tail which looks like as a small annelids or insect larvae. In addition, swimming cercariae in the water are sometimes attached to each other by the holdfast organ of the tail end. The cercarial body is somewhat opaque due to the densely compacted cystogenous materials. There are at least two kinds of such materials, i.e. a lod-like one and a granulated one. No trace of penetrating gland 
cells can be observed. A caudal excretory tube following the excretory bladder runs backwards in the tail, then it divides into two short branches and opens on the lateral side of tail at about anterior one third. The young redia has two pairs of prominent locomotive appendices, but it is not so prominent in the mature redia (Figs. 4 \& 5). Many sensory hairs at the anterior tip of the body and ten pairs of flame cells in the body wall are recognized in both rediae of mature and immature. The flame cell formula of redia is generally represented as $2[(5+5)]=20$, with some variations.

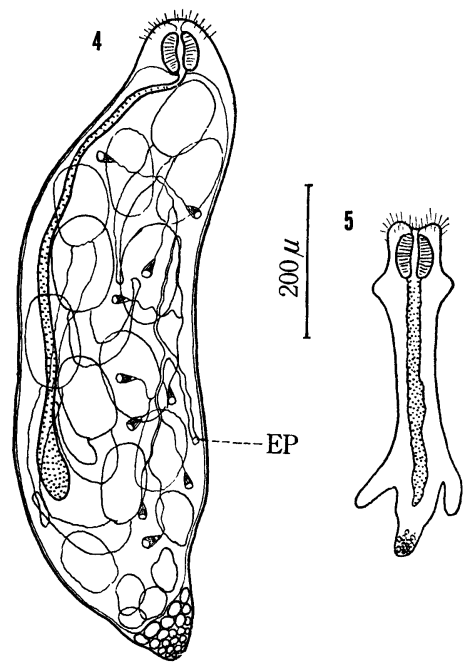

Fig. 4. Mature redia of C. chromatocerca.

Fig. 5. Young redia of C. chromatocerca.
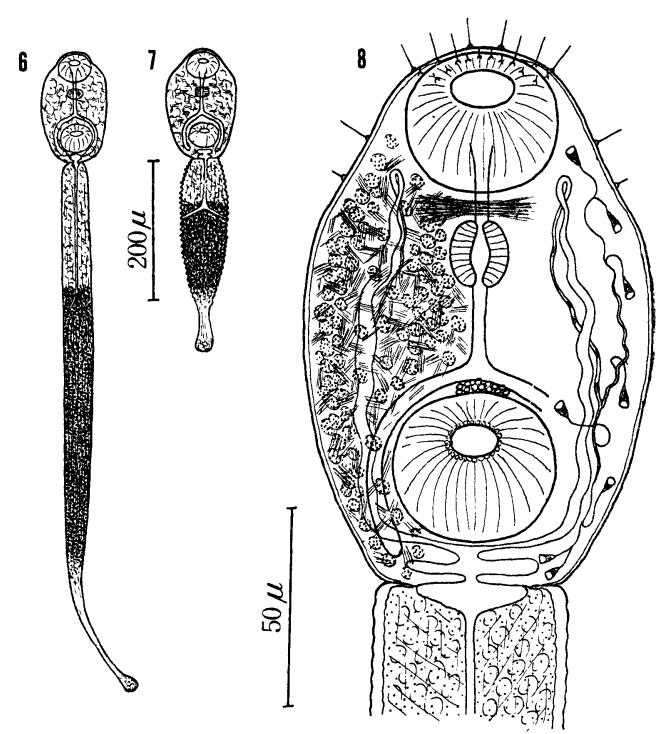

Fig. 6. Cercaria of C. chromatocerca, showing an elongated tail.

Fig. 7. Ditto, showing a contracted tail.

Fig. 8. Ditto, showing a detailed structure of the body.

Discussion...... Lühe (1909) created a new group name "Rattenkönig Cercarien " for such cercariae, and it was renamed by Brumpt (1936) as "Zygocercariae". Several species of "Zygocercariae" has been reported by the Japanese investigators from Japan and adjacent territories. They are as follows : cercaria of Echinochasmus milvi by Koga (1952) from Semisulcospira libertina in Ooita Prefecture, Cercaria $s p$. by Yamaguti (1951) from the same snail in Shiga and Gumma Prefectures, Cercaria radiata by Komiya (1941) from Melanoides fortunei in Shanghai, Cercaria sp. 3 by Yokogawa \& Wakeshima (1934) from S. libertina in Formosa. Cercaria contractilis by Kobayashi (1922) from the same snail in Korea may perhaps be the member of this group, as far as the brief original description shows.

The present species has a strong resemblance to the cercaria of Echinochasmus milvi, but differs from it in the body size, flame cell formula, and tail colouration, etc. So the new name, Cercaria chromatocerca, is given for the present cercaria. 


\section{Cercaria creta Faust, 1924 (Figs. 9-11)}

The author obtained one species of xiphidiocercaria, which was identifiable as Cercaria creta, on two occasions from Semisulcospira libertina. One was from Yamanashi Prefecture in 1947, and the other from Okayama Prefecture in 1952. The name, Cercaria creta, was given by Fasut (1924) for "Xiphidiocercaria K" of Kobayashi (1922) who obtained it from the same species of snails in Korea. Though the original description and figure of Kobayashi is very incomplete, the present species agrees entirely with Cercaria creta, as far as the original description shows. The following is a detailed morphological descriptions of this cercaria

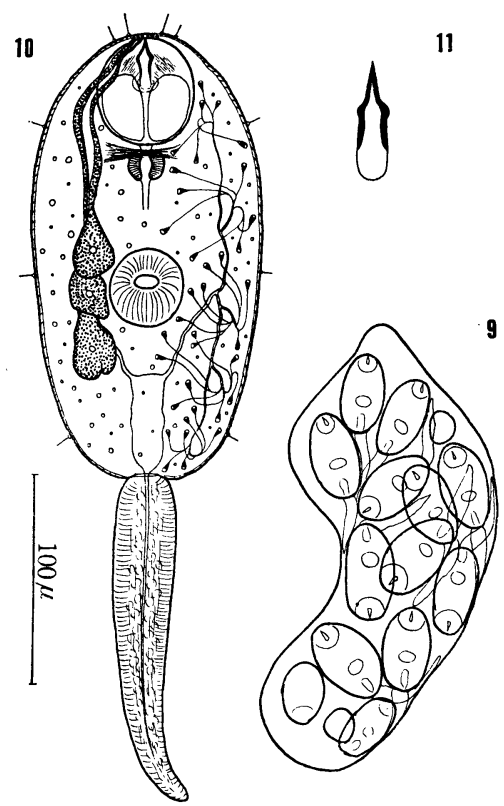

Fig. 9. Sporocyst of C. creta.

Fig. 10. Cercaria of C. creta.

Fig. 11. Ditto, the stylet.

Parthenita (Fig. 9)......The parthenita is a colourless, irregular ellipsoidal shaped sporocyst. It measures $0.4-0.8$ (av. 0.6 ) $\mathrm{mm}$ in length and $0.15-0.35$ (av. 0.27) $\mathrm{mm}$ in width. The body surface has neither hair nor spine. Matured sporocyst contains equally developed cercariae, the number of which is usually ten to thirty.

Cercaria (Figs. 10-11)...... This is a xiphidiocercaria belonging to Virgula group of Sewell (1922). The measurements of cercariae are as follows :

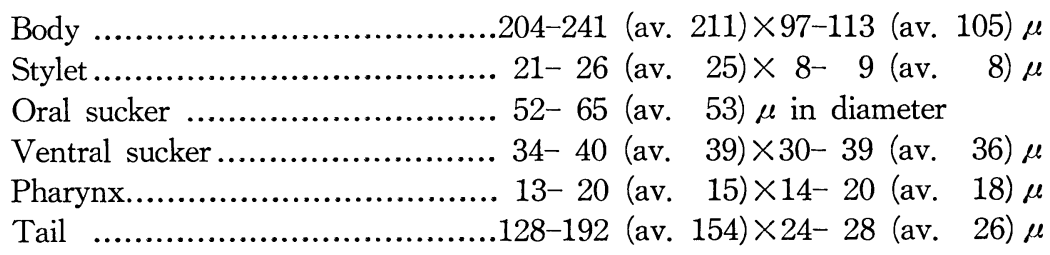


The body is a middle sized ellipsoidal or oval in shape, and entirely transparent. The body surface is beset with many minute spines and several pairs of sensory hairs standing on a papilliform base respectively. Many variously sized and strongly refractive granules are scattered in the body cavity, appearing like oil droplets. The oral sucker is comparatively large in size, but not so well developed. One pair of so-called virgula organ occupies the major space within the oral sucker. It does not show any differential structure, and looks somewhat incompletely developed. A well developed and sharply pointed stylet has a swelling ring at the level of its anterior one third, and a broad soft base at its posterior part. Incessant moving of the stylet is due to the fine muscle bundles attaching to the base of stylet. A ventral sucker, situated slightly posteriorly from the middle of body, is smaller but rather stronger than the oral sucker. A short prepharynx is followed by a small pharynx and a faintly recognized esophagus. No ceca are observed. There are three pairs of penetrating gland cells at both lateral sides of acetabulum. The third pair of them are more coarsely granulated stainig densely with neutral red than the other pairs. Their ducts run forwards separately and open on the anterior tip of the body.

An I-shaped anepithelial excretory bladder is situated at the posterior part of the body. From the antero-lateral corner of it one pair of main excretory collecting tubes arise and run forwards in zigzag course to the level of acetabulum, where they divide into an anterior and a posterior collecting tube respectively. Unexpectedly complicated flame cell pattern puzzled me very much, and the materials were too insufficient to determine its formula. A fundamental flame cell formula may tentatively be constructed as $2[(6+6)+$ $(6+6+6)]$ including many variations, such as 8 or 9 instead of 6 in each group as figured in Fig. 10.

A tail connecting with the ventral posterior end of the body, is weakly developed and shorter than the body length. It is coated with a thin cuticle without any spine nor hair.

\section{Cercaria innominatum Faust, 1924 (Figs. 12 \& 13)}

This cercaria was discovered from several areas and in every seasons from Semisulcospira libertina in Shizuoka Prefecture, its infection rate was 21 out of 34060 , or $0.06 \%$. As far as the brief original descriptions show, this cercaria is identifiable with "Cercaria $\mathrm{H}$ " of Kobayashi (1918) and "Cercaria sp. 8" of Ando (1918), though some slight differences exist in their descriptions. Faust (1924) gave them a proper name, Cercaria innominatum, without any descriptions. So the present cercaria is described in details under the name, Cercaria innominatum, in the following.

It is addendumly noted here that "Cercaria T" of Ueno et al. (1930) and the present cercaria would be the same species as far their description shows.

Parthenita (Fig. 12)..... The parthenita is an ellipsoidal or globular shaped redia in large size, measuring $0.8-1.9$ (av. 1.2) $\mathrm{mm}$ in length, and $0.4-0.6$ (av. 0.5) $\mathrm{mm}$ in width. The body wall is thick and contains a lot of dark brownish pigments. At the posterior part of redia, there exists one pair of excretory pores, from which a main collecting tube arises and runs forwards in zigzag course to the level of middle part of the body respectively. Then the tube divides into an anterior and a posterior tubule, each of which receives several number of flame cells. A mouth is terminal, and a birth pore is at the slightly posterior opposite corner. A well developed large pharynx measures 176-235 (av. 210) $\mu$ in diameter. A globular shaped intestine, measuring 0.3-0.7 (av. 0.5) mm 
in length and $0.2-0.4$ (av. 0.34 ) $\mathrm{mm}$ in width, occupies a large space of the body cavity. The conspicuous appearance of the intestine is due to many densely compacted granules coloured in light brown or orange. Several variously developmental stages of cercariae are contained in the body cavity of redia.
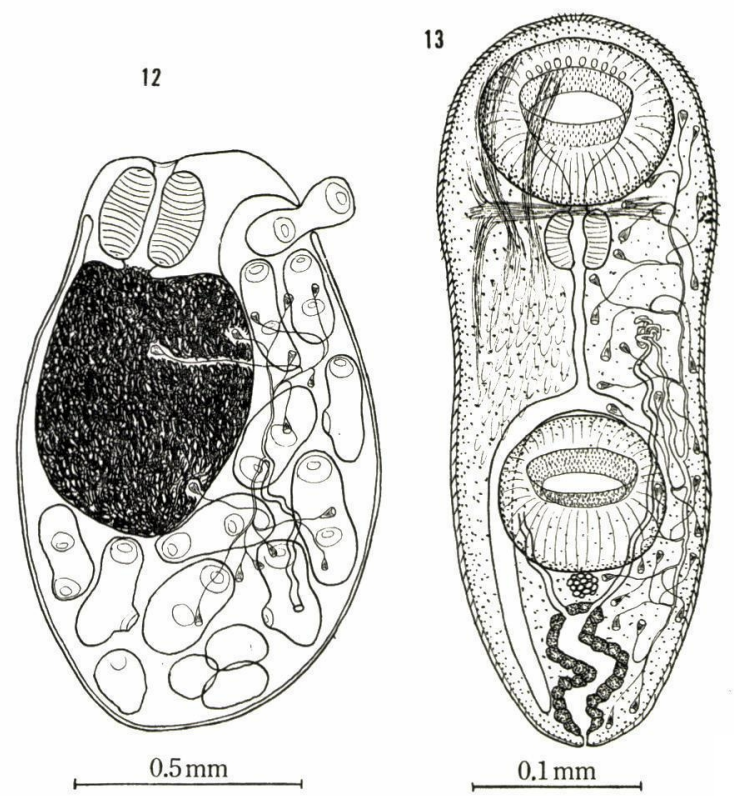

Fig. 12. Mature redia of C. innominatum.

Fig. 13. Cercaria of $C$. innominatum.

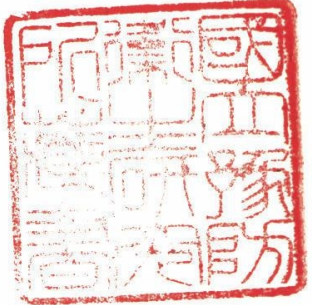

Cercaria (Fig. 13)......This tailless large cercaria has a vigorous power of creeping by the aid of prominent oral and ventral suckers. The measurements made on 10 specimens fixed in 10\% hot formalin are as follows :

Body .........................396-476 (av. 432) $\times 131-174$ (av. 156) $\mu$
Oral sucker........................ 92-122 (av. 103) $\times 107-128$ (av. 114) $\mu$
Ventral sucker ................... 82-107 (av. 92) $\times 92-110$ (av. 99) $\mu$
Pharynx ........................ 31-37 (av. 36) $\times 34-46$ (av. 40) $\mu$

The body shape is ellipsoidal, being more blunt at the anterior end than at the posterior one, and being widest at the level of esophagus. A thick body wall is provided with many minute spines directing their tips backward. They arrange in quincunxes, and more densely distribute in the anterior part. No sensory hair is observed. Many light brownish pigments depositing in the body cavity make the body somewhat opaque. An oral sucker is very large and has a large opening provided with five rows of circularly arranged pointed spines $2.5 \mu$ long. At the anterior margin of the opening is also found one row of small papillae, the number of which varied from 9 to 11 . A globular acetabulum is slightly smaller than the oral sucker and is located at the posterior two thirds of body. There are found seven rows of circularly arranged pointed spines 
surrounding the opening of acetabulum. This acetabulum is very thick and muscular and has a prominent power of protrusion.

The mouth opening is followed by an extremely short prepharynx and a well developed globular pharynx. The long and narrow esophagus runs backwards and divides into two ceca in front of the acetabulum. Each cecum reaches the posterior end of the body. Many glandular cells are faintly recognized at both sides of the esophagus, and from these cells two pair of duct-like bundles run forwards to the anterior end of body. These are presumably the rudiments of penetrating glands.

A thick walled epitherial excretory bladder occupies the posterior part of the body. It is usually winding in S-shape. From its antero-lateral corner one pair of main collecting tubes run forwards reaching the level of esophagus, where they convolute and turn back to both sides of acetabulum. Then they divide into an anterior and a posterior collecting tubes respectively. The anterior collecting tube runs forwards giving off four branches in the course and terminates in three flame cells. The above mentioned four branches also seemed to receive three flame cells respectively in general, though there are some variations in some specimens. The posterior collecting tube runs backwards and receives also 30 or more flame cells as the anterior one does so. Thus the flame cell formula is fundamentally constructed as follows with some variations :

$$
2[(3+3+3+3+3)+(3+3+3+3+3)]=60 .
$$

A nervous commissure is located across the prepharynx. The genital primordium is recognized at the position between the acetabulum and the excretory bladder.

\section{Cercaria monostyloides n. sp. (Figs. 14 \& 15)}

Host : Semisulcospira libertina (Gould).

Locality: Shizuoka Prefecture, Japan.

Specific diagnosis : Tailless cercaria of $354-427$ (av. 402) $\mu$ long by 97-128 (av. 113) $\mu$ wide. Body is cylindrical, being blunt in anterior part and protruded in posterior extremity. Body surface is covered with many minute spines but no sensory hair. A well developed oral sucker, 52-67 (av. 59) $\mu$ long by $52-61$ (av. 59) $\mu$ wide, is spherical and terminal. A single pointed stylet is embedded in it. The size of this stylet is not constant but varies from 4 to $10 \mu$ long by from 1.3 to $2.3 \mu$ wides sometimes being absent in immature cercariae. Extremely minute spines are arranged in three rows around the mouth opening. Their number are from 15 to 20 in each row. An acetabulum, larger than the oral sucker, measuring 55-67 (av. 61) $\mu$ long 61-67 (av. 65) $\mu$ wide, is at the middle of the body. Its opening is provided with many minute spines in concentric circles.

The mouth opening is followed with a long prepharynx of 15-46 (av. 31) $\times 3.5-7.6$ (av. 5.4) $\mu$, and an ellipsoidal pharynx of 24-31 (av. 28) $\times 25-34$ (av. 30) $\mu$. An esophagus is divided just in front of the acetabulum into two long ceca extending to the posteior end of the body. Penetrating gland cells are faintly recognized, from which two bundles of their ducts run forwards and open at the anterior extremity. A nervous commissure is recognized across the prepharynx. A genital primordium is found behind the acetabulum as a mass of cells.

An I-shaped epithelial excretory bladder is at the posterior part of the body. One pair of main collecting tubes from its antero-lateral corner run forwards in zigzag course, turn back making a loop at the level of pharynx, and divide into an anterior and a posterior collecting tube at the level of the anterior margin of acetabulum respectively. The flame cell formula is demonstrated as $2[(4+5+$ $5)+(5+5+5)]=58$.

A large ellipsoidal shaped redia measures $0.3-0.7 / 0.1-0.3 \mathrm{~mm}$. The anterior end is more blunt than the posterior end. Many sensory hairs are on the anterior body surface, especially around the mouth opening. In the body wall are one pair of excretory pores, from which one pair of main collecting tubes arise and run forwards. Flame cell formula is $2[(3+3)]=12$ with some variations. A well developed pharynx, about $55 \times 45 \mu$ in size, is followed by a long intestine reaching the level of the posterior one fourth of the body. It contains many brownish granules in its cavity. Several cercariae and a small number of germ balls are observed in the redial body cavity. 
The present cercaria was obtained from several areas in each season, though its infection rate was not so high. As a result of the comprehensive survey in Shizuoka Prefecture, 150 out of 34060 , or $0.4 \%$, of snails were infected with this cercaria. The cercaria creeps vigorously and varies in its body shape from cylindrical to pisiform, fusiform, oval, ellipsiodal, etc.

The minute spines on both anterior and posterior ends are larger and more densely distributed than the spines on the other body surface. They measured $2-5 \mu$ in length. It is characteristic of this cercaria that the length of stylet varies very much. Sometimes it is not detectable in young cercaria, especially in cercaria within a redia. It is presumable that the stylet develops more slowly than the other general structures do.

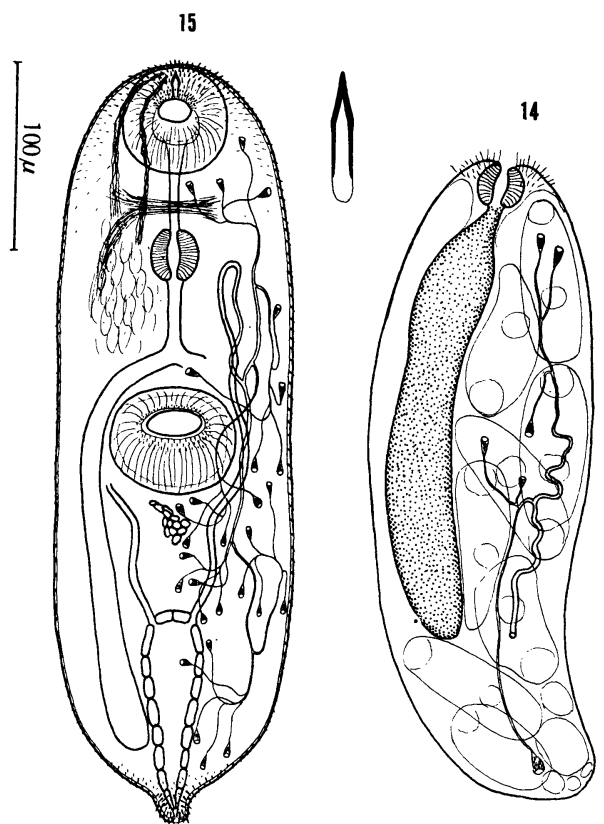

Fig. 14. Mature redia of C. monostyloides.

Fig. 15. Cercaria of C. monostyloides.

Discussion......Tailless cercariae with much resemblance had been reported in Japan by Nakagawa (1915), Yoshida (1917), and Ando (1918), namely, "Cercaria XVII" of Nakagawa, "Cercaria E" of Yoshida, and "Cercaria XIII" of Ando. Kobayashi (1922) dealt with these three species as the same one, though there exist some differences among the three descriptions. The author agrees with Kobayashi's opinions, and the present cercaria is identifiable with the above mentioned species.

Faust (1924) erroneously identified the above mentioned cercaria with Cercaria mutabile Cort, 1919. It is not reasonable because Cercaria mutabile was proved to develop to Triganodistomum mutabile by Wallace (1941) in America. No Triganodistomum was reported in Japan, and no intermediate snail host was detected in Japan. So the author proposes a new name, Cercaria monostyloides, for the present cercaria, including the three descriptions reported earlier. 
Besides, one tailless cercaria which closely resembled this species was reported by Ueno et al. (1930). This was presumably the same species of the present one, though the body length was much larger.

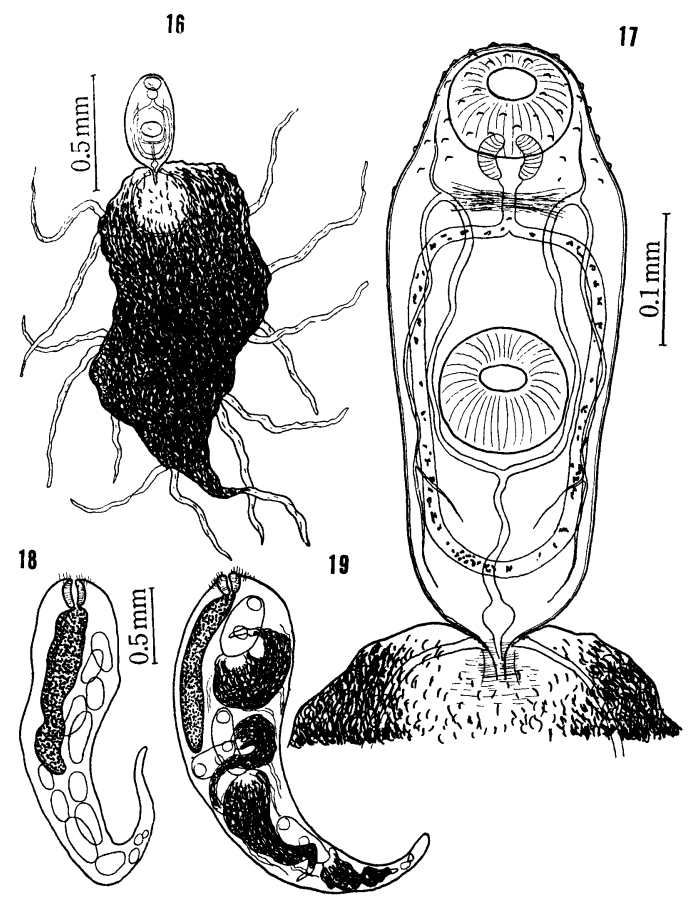

Fig. 16. Cercaria of C. manei.

Fig. 17. Ditto, showing a detailed structure of the body.

Fig. 18. Immature redia of C. manei.

Fig. 19. Mature redia of $C$. manei.

\section{Cercaria manei n. sp. (Figs. 16-19)}

Host: Semisulcospira libertina (Gould).

Locality: Shizuoka Prefecture, Japan.

Specific diagnosis : Cysticercous cercaria of 358-505 (av. 448) $\mu$ long by 135-193 (av. 158) $\mu$ wide, with an extremely large black coloured tail. The entirely transparent body is ellipsoidal in shape, being widest at the level of esophagus. It has neither spines nor hair, but several papillae on its anterior surface. A well developed oral sucker, 66-90 (av. 80) $\mu$ long by 85-95 (av. 90) $\mu$ wide, is at the anterior end. An acetabulum, larger than the oral sucker, 87-98 (av. 94) $\mu$ long by 93-100 (av. 97) $\mu$ wide, is at the level of three fifth from the anterior tip of the body. No prepharynx. A well developed muscular pharynx, measuring $32-45$ (av. 38) $\times 44-53$ (av. 48) $\mu$, impinges on the oral sucker and is followed by a short esophagus which divides into two ceca finally joining each other in front of the excretory bladder. Fragmental food granules are scattered in the ceca. Penetrating glands and cystogenous glands are not observed.

A small anepithelial excretory bladder is globular, frcm its antero-median part one main collecting tube arises and passes forwards up to behind the acetabulum, where it divides into two lateral collecting tubes. These tubes run forwards surrounding the acetabulum and attain to the lateral side of the esophagus where each tube divides into an anterior [and a posterior collecting tube respectively. The flame cell formula could not be determined. 
A tail, $0.8-1.2 \mathrm{~mm}$ (av. $0.959 \mathrm{~mm}$ ) in total length and $0.3-0.6 \mathrm{~mm}$ (av. $0.453 \mathrm{~mm}$ ) in width, is irregular fusiform in shape. It is entirely black in colour except the anterior part. It is provided with a number of filament appendages. They are colourless, 11-18 in number, and 360-630 (av. 466) $\times 21-32$ (av. 27) $\mu$ in size. A thick walled cavity, 158-233 (av. 190) $\times 140-210$ (av. 153) $\mu$ in size, is located at the anterior part of the tail.

The parthenita is a redia of $0.8-2.5 \mathrm{~mm}$ long by $0.4-0.6 \mathrm{~mm}$ wide. Its anterior part is bluntly rounded and the posterior part, moving actively, is sharply elongated. It has neither collar nor locomotive appendix. Many minute sensory hairs are found at the anterior end. A pharynx, about $80 \times 60 \mu$, is followed by a orange-coloured long intestine. A matured redia harbours a few cercariae in the cavity, the number of which is usually from 2 to 7 .

Discussion......The above mentioned cercaria is a rare species. Only three out of 34060 snails harboured this cercaria in Iwata City, Shizuoka Prefecture. Its life history is not known, though presumably eaten by a second intermediate host passively.

There has been no report of such cercaria except a brief description of Ueno, Ishii, $\&$ Abe (1930), who obtained it from Semisulcospira libertina in Kumamoto Prefecture, and denominated it as "Cercaria F". As far as their description is concerned, they are dealing with the same species as the present one. The present author proposes to give a new name to the above mentioned cercaria as Cercaria manei n. sp.

\section{SUMMARY}

Seven species of cercariae in Semisulcospira libertina obtained from Japan are redescribed or described. Cercaria pseudodivaricata Faust, 1924 is classified as a furcocercous type, presumably belonging to the family Diplostomatidae. Cercaria radicola Faust, 1924 is also classified as a furcocercous type possessing a character of Vivax group. Cercaria chromatocerca $\mathrm{n}$. sp. is classified as an echinostome type and has the character of Zygocercariae. It has a close resemblance to the genus Echinochasmus. Cercaria creta Faust, 1924 is classified as a virgulate xiphidiocercariae. Cercaria innominatum Faust, 1924 and Cercaria monostyloides n. sp. are both of a tailless types; the former has a large size and the latter has a middle size. Cercaria manei n. sp. is a peculiar cysticercous type possessing a black coloured fusiform tail.

\section{REFERENCES}

ANDO, R. (1918): Studies on the cercariae in Semisulcospira libertina from an endemic area of lung fluke in Gifu Prefecture (Addition of 6 species of cercariae). "Chuo Igakkai Zasshi", 141, 610-627 (text in Japanese).

BRUMPT, E. (1936): Precis de Parasitologie 1, pp. 563.

FAUST, E. C. (1924): Notes on larval flukes from China. II. Studies on some larval flukes from the central and south coast provinces of China. Am. J. Hyg., 4, 241-301.

Hoffman, G. L. \& Hundley, J. B. (1957): The life cycle of Diplostomum baeri eucaliae $\mathrm{n}$. subsp. (Trematoda: Strigeida). J. Parasitol., 43, 613-627.

KomiYA, Y. \& ITO, J. (1950): Contributions to the morphology of Paragonimus westermanii. Jap. M. J., 3, 309-314.

ITO, J. (1952 a): Redescription of Cercaria nipponensis Faust, 1924, a xiphidiocercaria in snail host Semisulcospira spp. in Japan. Jap. J. M. Sc. \& Biol., 5, 13-20.

ITO, J. (1952 b) : Redescription of Cercaria yoshidae Cort et Nichols, 1920, a cystophorous cercaria in the snail, Semisulcospira spp. in Japan. Jap. J. M. Sc. \& Biol., 5, 447-454.

ITO, J. (1953 a) : Redescription of Cercaria incerta Faust, 1924, a cotylomicrocercous cercaria in snail host Semisulcospira spp. in Japan (Trematoda). Jap. J. M. Sc. \& Biol., 6, 289-293.

Iто, J. (1953 b) : Two cystophorous cercariae, C. introverta Faust, 1924, and C. longicerca $\mathrm{n}$. sp. 
from fresh water snail, Semisulcospira spp. in Japan, with a list of cystophorous cercariae. Jap. J. M. Sc. \& Biol., 6, 487-492.

ITO, J. (1956) : Study on the cercaria and metacercaria of Pseudexorchis major (Hasegawa, 1935) Yamaguti, 1938, especially on the development of its metacercaria, (Heterophyeidae, Trematoda). Jap. J. M. Sc. \& Biol., 9, 1-16.

Ito, J. \& WATANABE, K. (1958): On the cercaria of Centrocestus armatus (Tanabe, 1922) Yamaguti, 1933, especially on its mucoid gland (Heterophyeidae, Trematoda). Jap. J. M. Sc. \& Biol., 11, 21-29.

ITO, J. (1958) : A monograph of Japanese cercariae, Part 1. Bull. Educational Faculty of Shizuoka Univ., No. 9, 200-222 (text in Japanese).

ITO, J. (1959): A contribution to the morphology of cercaria of Notocotylus magniovatus Yamaguti, 1934 (Notocotylidae, Trematoda). Jap. J. M. Sc. \& Biol., 12, 133-137.

ITO, J. \& WATANABE, K. (1959): Studies on Mucoid glands in the cercaria of Notocotylus magniovatus Yamaguti, 1934 (Notocotylidae, Trematoda). Jap. J. M. Sc. \& Biol., 12, 139-143.

ITO, J. (1960): Studies on the morphology and life cycle of Pseudobilharziella corvi Yamaguti, 1941 (Trematoda: Schistosomatidae). Jap. J. M. Sc. \& Biol., 13, 53-58.

ITO, J., Mochizuki, H. \& NoGuchi, M. (1959): Studies on the cercariae parasitic in Semisulcospira libertina in Shizuoka Prefecture. "Kiseichu-Gazu Zasshi", 8, 913-922 (text in Japanese with English summary).

KoBAYASHI, H. (1922): A review of Japanese cercariae. "Dobutsu-Gaku Zasshi”, 34, 252-270 (text in Japanese).

KOGA, Y. (1952): Studies on the life histories of the trematodes belonging to the family Echinostomatidae. I. On the life history of Echinochasmus milvi Yamaguti. "Kurume Igakkai Zasshi ', 15, 393-405 (text in Japanese with English summary).

KomIYA, Y. (1941) : A new “Zygocercaria”, Cercaria radiata, and its excretory system (Cercariae from Chinese fresh water 3). J. Shanghai Sc. Inst., 1, 229-232.

Lühe, M. (1909): Parasitische Plattwürmer. I. Trematoda. Die Süsswasserfauna Deutschlands, 19, 173-210.

NAKAGAWA, K. (1915): On the cercaria of fresh water snails in Shinchiku Province, Formosa. "Taiwan Igakkai Zasshi ", 148, 107-120 (text in Japanese).

UENO, N., IsHII, K. \& ABE, H. (1930): On the cercariae parasitic in fresh water snails at the neighbourfood of Kumamoto Prefecture. "Kumamoto Igakkai Zasshi", 6, 965-976 (text in Japanese).

WALlACE, H. E. (1941): Life history and embryology of Triganodistomum mutabile (Cort), (Lissorchiidae, Trematoda). Trans. Am. Micro. Soc., 60, 309-326.

YAMAGUTI, S. (1951): On the Japanese Rattenkönig cercariae. "Nippon Kiseichu Gakkai Kiji", 20, 20-21 (text in Japanese).

YokOGAWA, S. \& WAKESHIMA, T. (1934): On the cercariae of Melania libertina from an endemic area of lung fluke in Shinchiku Province, Formosa. " Tokyo Iji Shinshi ", 2873, 861868 (text in Japanese).

YoshidA, S. (1917): Studies on the cercariae of Melania spp. "Dobutsu-Gaku Zasshi ", 29, 1 . 17 (text in Japanese). 